\title{
ARBITRARIEDAD EN LAS DECISIONES JUDICIALES Y ADMINISTRATIVAS
}

\author{
Autores: Medina Solano Stephanie Mariana'; Carmona Vergara Heyllyn Valeria² \& Mejía Turizo \\ Jorge $^{3}$
}

Correspondencia: Stephabie Mariana Solano Medina en: phanie0525@hotmail.com

\section{RESUMEN}

En el presente artículo de reflexión se esbozaran los elementos que permiten concluir que una actuación judicial o administrativa es arbitraria, en las que por lo general, los funcionarios que se encuentran en posición dominante hacen uso de la misma para tomar decisiones en la que priman intereses más allá de lo perseguido por la ley, esto es, aspiraciones personales, alejadas de todo concepto permitido dentro de la discrecionalidad y del imperio de la ley, rompiendo los principios de legalidad, debido proceso y equidad, contemplados en la Constitución Nacional como garantía de los derechos de los ciudadanos dentro de un Estado Social de Derecho.

\section{Palabras clave:}

Arbitrariedad judicial, Arbitrariedad administrativa, Abuso del poder, Interpretación, Leyes, Sentencia judicial, Acto administrativo

\section{ABSTRACT}

In the present reflection article, presents the elements to conclude that a judicial or administrative action is arbitrary, which usually officials are dominant make use of it to make decisions that puts interests beyond persecuted by law, that is, personal aspirations, away from any concept allowed within the discretion and the rule of law, breaking the principles of legality, due process and fairness, referred to in the Constitution as a guarantee of the rights of citizens within the rule of law.

\section{Keywords:}

Judicial arbitrary, administrative arbitrariness, abuse of power, law judgment, administrative act.

\section{INTRODUCCIÓN}

\footnotetext{
1 Estudiante de Decimo Semestre de Derecho de la Universidad Simón Bolívar de Barranquilla. En: phanie0525@hotmail.com.

2 Estudiante de Decimo Semestre de Derecho de la Universidad Simón Bolívar de Barranquilla. h.vale.carmona@hotmail.com.

${ }^{3}$ Abogado, Magister en Derecho Administrativo, Diplomado en Gestión y Políticas Públicas de la ESAP, Ex Becario del Programa Jóvenes Investigadores e Innovadores de Colciencias. Docente investigador en el Programa de Derecho Corporación Universitaria Rafael Núñez, Sede Barranquilla.
} 
Una de las necesidades vitales para el desarrollo armónico de una sociedad sin duda alguna es la justicia, ahora bien, cuando se hace alusión a la administración de justicia, puede concebirse como aquella función pública que recae en el Estado con el fin de garantizar a sus asociados el cumplimiento de los derechos y deberes plasmados en el ordenamiento jurídico, por lo que desde la antigüedad y los inicios del derecho han surgido diferentes formas de hacer justicia, sea por propia mano o por la de un tercero imparcial, tales como la venganza privada, la ley del talión, las ordalías o juicios de Dios, hasta llegar a las estructuras modernas de los aparatos de justicia.

La venganza privada, originada en clanes y tribus, en los que aun no existían concepciones de derecho y de justicia, y que consistía básicamente en que "cuando el individuo o sus parientes recibían una afrenta, podían hacerse justicia mediante una retaliación o represalia realizada por el propio ofendido, o como se dijo, sus parientes" (Velásquez, 2010, p. 221) cuya característica principal era la omisión del principio de proporcionalidad.

Posteriormente, con la aparición del Código de Hammurabi nace la denominada Ley del Talión como un sistema para impartir proporcionalidad de un daño causado y un castigo recibido, la Ley del Talión tiene una tendencia religiosa plasmada en las escrituras del libro del éxodo "ojo por ojo, diente por diente", esta figura limito sin duda alguna la venganza privada, dándole un poco mas de equidad a estas acciones.

Las ordalías en la Edad Media no eran más que someter a quien hubiesen cometido la falta a una serie de pruebas físicas para probar su inocencia o culpabilidad donde Dios era el encargado de manifestar en su "voluntad" si la persona era culpable o no, dándole a este el papel de juez o de un tercero que 
definiera dicha situación, ya con la necesidad que poco a poco iba surgiendo la aparición de un derecho probatorio, llamándose también "juicios de Dios".

Desde la época donde se usaban las ordalías o justicia de Dios, con el tiempo fueron surgiendo necesidades que ya este sistema no podía sostener y fue ahí cuando se dieron los primeros pasos para lograr una justicia equitativa, dando lugar a la etapa moderna que invocaba una justicia humanista, también llamado el periodo de las luces el cual originó lo que más adelante seria la reconocida Revolución Francesa, que a través de ella se dieron las condiciones para "hacer la Declaración Oficial de los Derechos del Hombre y del Ciudadano" (Rodríguez, 2011, p. 27).

Este articulo estará centrado en la arbitrariedad que recae en las decisiones judiciales y administrativas, teniendo en cuenta que son las que más repercusiones tienen en el diario vivir de los ciudadanos. Hay arbitrariedad en las decisiones sean judiciales o administrativas, cuando se abusa del poder político o judicial de quien se encuentra en posición dominante con respecto a los particulares; y cuando dicho funcionario no interpreta bien una norma o cuando realiza una interpretación ajustándola a su conveniencia o a la de un tercero.

\section{MATERIALES Y MÉTODOS}

La investigación fue abordada a través de las lecturas e interpretación realizadas a los textos relacionados con la materia.

\section{RESULTADOS Y DISCUSIÓN}

\section{Antecedentes y origen de las decisiones}


Con la Revolución Francesa en 1789, luego de la lucha por encontrar una equidad entre el estado y los derechos de sus asociados, se da el nacimiento del Estado de Derecho, que traería consigo un estado que no solo impondría la ley si no que también se sometería a ella "de la ley del imperio, al imperio de la ley" y junto con todo esto la tridivisión del poder en ramas separadas e independientes, dejando la monarquía de lado, ya que esta no teniendo quien la juzgara incurría en arbitrariedad.

Dice Henao refiriéndose al "El Estado de Derecho ha virado hacia el Estado Social de Derecho, en especial con una respuesta a las nuevas exigencias a los países europeos por la Primera Guerra Mundial (1914-1918) y, con más fuerza aun, por la Segunda Guerra Mundial (1939-1945)". (2013, p.137). El naciente Estado Social de Derecho, mantiene los principios y estructura jurídica del Estado de Derecho, pero buscando una interacción en las actividades sociales de sus asociados. Esto fue lo que adoptó el constituyente en 1991, con motivos claros, como satisfacer las necesidades de los asociados puesto que "este Estado Social de Derecho en cumplimiento de sus objetivos debe servir como protector de los necesitados y garantizar el bien común" (Abello, 1998, p.84).

Entonces, ya acontecido los anteriores hechos que dieron origen al Estado Social de Derecho junto con la nueva Constitución del año de 1991, donde se le da como tal, la inclusión en el contexto jurídico. Teniendo así "el Estado Social de Derecho como presupuesto la dignidad humana" (Younes, 2014, p.14), lo que se resume en otras palabras que prevalecen los derechos de cada persona sobre las instituciones del Estado. Aparecen nuevos derechos que fortalecen la capacidad legal de cada individuo frente a otras personas y el estado.

En esta adopción del Estado Colombiano se pueden cometer errores jurídicos y administrativos cuando se desconoce la magnitud que implican los conceptos que conforman la dignidad humana, presentándose la arbitrariedad, 
Vol. 6, No. 1 Diciembre de 2014 pp. 150 - 164

pero no como abuso del poder o haciendo mal uso de la posición dominante en la que pueden encontrase los jueces y las autoridades administrativas, sino en la interpretación que se le da a una norma, donde la autoridad competente se halla en una disyuntiva en si darle prevalencia a los derechos fundamentales o a los derechos de las instituciones del Estado.

\section{Concepciones de arbitrariedad en el contexto jurídico}

La arbitrariedad es un sustantivo derivado del adjetivo arbitrario, procedente del latín arbitrarius y que lo explica Fernández (2008) en los siguientes términos:

Originariamente arbitrarius es lo referente al árbitro, que no es sino un ciudadano Romano al que el pretor asigna la decisión en la fase apud iudicem de un proceso, cuyos términos concretos el propio pretor ha fijado previamente en la fase in iure, de forma que aquel solo tiene que comprobar la realidad de los hechos generadores del litigio y aplicar a lo que resulte probado la formula preestablecida. La libertad del árbitro es, en realidad, mínima por esta razón y, desde luego, no entran inicialmente en ella ni la nuda voluntad, ni el mero capricho de aquel, que la idea republicana de las libertas, por otra parte, excluye. (p.149).

\section{Arbitrariedad en las ramas del poder público}

Viendo la arbitrariedad desde un enfoque jurídico "comprende lo injusto, irrazonable e ilegal, fundado en la sola voluntad del funcionario siendo uno de los limites sustantivos de la discrecionalidad" (Cassagne 2009, p.196). Si se plasma lo anterior en las tres ramas del poder público, se observa que pueden surgir diferentes errores en las decisiones que se toman por quienes representan dichos poderes. 
En la Rama Ejecutiva que se encuentra representada por el gobierno nacional, departamental y municipal, pueden surgir arbitrariedades en el momento en que quienes se encuentran en cabeza de ellas crucen el límite y quieran sobrepasar a las otras dos ramas; un claro ejemplo podría ser que el Presidente de la República como máxima autoridad del ejecutivo, sin estar investido de jurisdicción decidiera de fondo en una Sentencia u ordenara la privación de la libertad a un individuo, acto totalmente erróneo e ilógico, puesto que esa conducta no está descrita dentro de sus funciones. Aquí estaríamos frente a un caso de abuso del poder o de invasión o usurpación de competencias.

También se está en frente a una arbitrariedad cuando el Jefe de Estado adopta un tratado o un pacto internacional y lo aplica en el territorio sin que el legislativo lo ratifique, o en el caso de que sin estar en estado de conmoción, tome atribuciones que no le corresponden en la creación de una ley, esto sería un retroceso del Estado Social de Derecho hacia un Estado Monárquico. El poder legislativo, conformado por el Congreso de la República, Senado y Cámara de Representantes, es quien tiene la facultad de crear las leyes, actividad que demanda una especial responsabilidad y por ende la posible comisión de actos arbitrarios, como por ejemplo que se apruebe una ley sin Quórum, ósea que no exista el número de congresistas que se necesitan como mínimo para sesionar para dicha aprobación, o que en las disposiciones de una ley se atente contra la constitución, sea contra un derecho fundamental o contra cualquier otro mandato dentro de la misma.

Ahora en cuanto a la Rama Judicial, esta es la encargada ya en concreto de administrar e impartir justica, es el poder donde se encuentra el conjunto de órganos e instituciones de las tres principales jurisdicciones y las Altas Cortes. El Poder Judicial tiene la responsabilidad de velar por el cumplimiento de las leyes y de supervisar que estas no vayan en contradicción a lo dispuesto en la 
Constitución. De las tres Ramas del Poder Público, la Judicial es en la que principalmente se presentan las arbitrariedades ya que es en ella donde los jueces deben darle una correcta interpretación a la norma manejando la discrecionalidad sin caer en el arbitrio.

Dice Fernández, "la discrecionalidad comporta una cierta libertad de elegir entre dos o más alternativas en principio posibles, jurídicamente posibles a la vista de la norma aplicable" (2005, p.25). Y a continuación agrega:

Kelsen (1953) afirmó que no hay diferencia esencial entre la preparación de una sentencia judicial o un acto administrativo conforme a la ley y la elaboración de una ley conforme a la constitución. La interpretación de la constitución no posibilita mas al legislador dictar una ley justa de lo que la interpretación de la ley posibilita a un tribunal pronunciar una sentencia justa. Entre estos dos casos, sin embargo, existe una diferencia de orden cuantitativo, ya que desde el punto de vista material la libertad del legislador es más amplia que la del juez, pero este también está llamado a crear normas jurídicas y goza de una cierta libertad en su actividad, puesto que la creación de una norma individual es un acto de voluntad en la medida en que se trata de llenar el marco establecido por la norma general. (p.169).

\section{Arbitrariedad en el abuso del poder}

Un funcionario público puede caer en arbitrariedad cuando abusa de su cargo, para emitir sentencias judiciales o actos administrativos a su voluntad, dejando a un lado los preceptos jurídicos establecidos para dirimir conflictos o sancionar algunas actuaciones. Este tipo de errores, son producto del abuso del poder, donde impera, sin duda alguna el pensamiento del autor y no el espíritu de 
la ley, considerando su ideología política, religiosa y cultural, olvidando el ordenamiento y actuando a su arbitrio caprichoso.

Un ejemplo claro puede ser el del funcionario del Ministerio Publico que destituye a un Servidor Público por hechos que no ameritan sanción, solo por una diferencia de concepciones o criterios políticos independientes. O como se expresa anteriormente quien usurpa las funciones de una rama del poder para lograr hechos que lo favorezcan políticamente, o simplemente para mostrar una jerarquía superior ante otras autoridades. Este abuso de poder también se observa en aquel que toma la norma y la aplica a su gusto, es lo que comúnmente se conoce como una tiranía, y se asocia con la monarquía, "en cuanto su ejercicio era despótico y completamente arbitrario." (Aristóteles, s.f) y más cuando era absoluta puesto que el poder recaía en una sola persona, no existía la separación de poderes y no había un control sobre las decisiones, el rey o monarca, "gobierna a súbditos que valen tanto o más que el sin consultar para nada los intereses particulares de los mismos. Este es un gobierno de violencia porque no hay corazón libre que sufra con paciencia una autoridad semejante" (s.f).

La diferencia entre ese gobierno y este estado social y democrático de derecho radica en que existen órgano de control judicial y legalidad, donde un funcionario de un rango superior analiza lo actuado y puede revocar o ratificar la decisión.

\section{Arbitrariedad por error en la interpretación}

La interpretación juega un papel fundamental al momento de aplicar la normatividad jurídica, de ésta depende la correcta impartición de justicia evitando por ende la arbitrariedad. La función que cumplen los jueces y los funcionarios administrativos investidos de función jurisdiccional es hacer uso de todo el ordenamiento jurídico, siendo los legisladores sus creadores y los jueces sus 
ejecutores, que tienen además la obligación de dirimir los conflictos sociales que se presenten entre sus asociados, estando siempre "sometidos al imperio de la ley" (Colombia. Asamblea Nacional Constituyente, 2001). Entonces la decisión judicial y administrativa ya no solo radica en el uso de la ley para llevarla a cabo, sino también en la interpretación que hace el juez sobre dichas leyes para resolver el problema jurídico, siendo ya necesario en este punto previo a la decisión hacer uso de la hermenéutica.

La hermenéutica propiamente dicha no es más que la interpretación en sentido propio de quien busca lograr la compresión; en el sentido jurídico, el juez haciendo uso de su discrecionalidad se encuentra en la "libertad" de interpretar la norma para posteriormente aplicarla, siendo específicamente esta línea la que permite incurrir en la arbitrariedad, y quizá no en una arbitrariedad voluntaria si no en una arbitrariedad por falla en la interpretación y esto ocurre cuando la ley o la norma no es lo suficientemente clara para poder tomar una decisión que de verdad de fin al conflicto, puede decirse que ese ordenamiento es oscuro o ambiguo, entonces es función del juez llenar ese vacío es decir, interpretarlo, comprenderlo y aplicarlo.

Esto porque "la interpretación del derecho es un acto de "integración", cuya base es el circulo hermenéutico (el todo debe ser entendido por la parte, y la parte solo adquiere sentido por el todo), siendo que el sentido hermenéuticamente adecuado se obtiene de las concretas decisiones por esa integración coherente en la práctica jurídica, asumiendo especial importancia a la autoridad de la tradición (que no aprisiona, pero funciona como condición de posibilidad), de acuerdo con la postulación de Streck. (2013, p.169).

\section{Arbitrariedad judicial}


Conservando el orden de ideas que se han venido desarrollando con respeto a la arbitrariedad judicial, se ubica a esta como el resultado de una decisión fundamentada en el mero antojo del funcionario que la emite, dejando de lado la normatividad jurídica. Las decisiones judiciales son las Sentencias y también los Autos, especialmente los interlocutorios proferidos por los jueces con el propósito de ponerle fin a un conflicto determinado. Todas las decisiones necesitan estar motivadas, solo algunas de ellas no lo requieren (Ejemplo: decretos de mero trámite) para poder dar fallo.

Cuando existe arbitrariedad en estos fallos, la persona en sobre quien recae puede interponer una Acción de Tutela ya sea por violación a sus derechos fundamentales o para que le sean garantizados. En lo que tiene que ver con la procedencia de la acción de tutela contra providencias judiciales, ésta resulta procedente en todos aquellos casos en los que la actuación de la autoridad judicial carezca de fundamento objetivo y sus decisiones sean el producto de una actitud arbitraria y caprichosa que traiga como consecuencia la vulneración de derechos fundamentales de la persona, incurriendo de esa manera en lo que se ha denominado como "vía de hecho".

Las "vías de hecho" implican una decisión judicial contraria a la Constitución y a la ley, que desconoce la obligación del Juez de pronunciarse de acuerdo con la naturaleza misma del proceso y según las pruebas aportadas al mismo. Los Servidores Públicos y específicamente los Funcionarios Judiciales, no pueden interpretar y aplicar las normas en forma arbitraria, pues ello implica abandonar el ámbito de la legalidad y pasar a formar parte de actuaciones de hecho contrarias al Estado de Derecho, que pueden ser amparadas u objeto de control o revisión a través de la Acción de Tutela. No toda irregularidad procesal genera una vía de hecho, más aún cuando quien se dice afectado tiene la posibilidad de acudir a los mecanismos ordinarios establecidos para solicitar la protección de sus derechos; pues no puede olvidarse que la Acción de Tutela "tiene un carácter subsidiario, es 
decir, que sólo es procedente a falta de otros mecanismos de defensa judicial" (Colombia. Corte Constitucional, 1995).

Sin embargo es importante tener en cuenta la facultad discrecional que tiene el juez para tomar sus decisiones claramente sin salirse del límite de esa libertad jurídica que se le confiere, "El Juez, dentro del ámbito de su competencia, goza de plena libertad para interpretar las disposiciones legales aplicables a un caso concreto, aun cuando dicha interpretación sea contraria a los intereses de las partes". (1995).

\section{Arbitrariedad administrativa}

Las decisiones administrativas no son más que aquellas que emanan de una autoridad que cumple una función en la administración pública, dichas decisiones reciben el nombre de actos administrativos, y son susceptibles de un control de legalidad, que por mandato constitucional lo ejerce la jurisdicción contenciosaadministrativa. En el cuerpo de estos actos, al igual que en una sentencia judicial, se debe tener en cuenta los derechos, deberes y libertades de cada individuo, no se pueden ignorar los principios que emana nuestra carta magna porque sería una decisión totalmente arbitraria.

Por el simple hecho de ser proferida por una autoridad administrativa se presume su legalidad, sin embargo no está exenta del control. Luego de la emisión de dicho acto se produce el efecto de cosa decidida lo que equivale a cosa juzgada en una decisión judicial.

Como ha sido señalado anteriormente, se comete arbitrariedad cuando se abusa del poder o cuando no se interpreta una norma de la manera adecuada lo que apunta directamente a quien decide, pues es él quien incurre en un error y provoca el rompimiento de los principios de legalidad y debido proceso, y exponiéndose a sanciones disciplinarias o un proceso penal, puesto que su 
"resolución, dictamen o concepto es contrario a la ley" como lo expresa el Código Penal. (Colombia. Congreso de la República, año). En el caso de los actos administrativos que resultan de la actividad sancionatoria de la Procuraduría General de la Nación, ha existido confusión pues este es un ente que no está adscrito a ninguna Rama del Poder, es de aquellas que dicen ser independientes, sin embargo el ejercicio de la potestad disciplinaria es una manifestación de la función administrativa por lo cual su control lo realiza la jurisdicción contenciosa, y ha resaltado el Consejo de Estado "que no es una tercera instancia disciplinaria" (Colombia. Consejo de Estado, 2013) haciendo alusión a que solo ejerce control de legalidad sobre dichos actos.

\section{Desviación de poder}

En este tipo de actuaciones se encuentra que también se puede configurar la desviación de poder como fuente de arbitrariedad, que no es más que la que se da cuando "el funcionario actúa con una finalidad distinta a la perseguida por la ley" (Gordillo, 2013, p 17).

Puede decirse que se incurre en desviación de poder cuando se toma la ley como un puente para conseguir fines como:

- Propios, ya sean de tipos políticos o económicos;

- De un tercero, cuando se obra para favorecer a personas del núcleo familiar o amigos;

- De la administración, cuando basado en concepciones equivocas y en una posición de poder supremo decide injustos que afectan a los asociados.

De esta manera, se está frente a una conducta antijurídica puesto que sus diligencias no estaban sujetas a sus funciones regladas previamente.

\section{CONCLUSIONES}


Para proferir decisiones judiciales o administrativas más que un grado de conocimiento amplio se requiere una formación moral, puesto que no solo se cometen arbitrariedades errando en la interpretación de una norma sino en el hecho de actuar a voluntad ignorando los derechos ajenos y todo por conseguir fines diferentes a los otorgados por la Constitución, lo que se puede determinar cómo desviación del poder.

Aunque dichas actuaciones tengan la presunción de legalidad, y además pasen por un control, es reprochable que el funcionario olvide el espíritu de la ley, independientemente de cuál sea el origen de la arbitrariedad. Eso ocurre cuando se anteponen intereses personales o simplemente no se actualicen en cuanto a las normas nacientes o no se comprenda realmente la intención del legislador. Ante ello es muy difícil no pensar en la elección de estas autoridades, en los criterios que se tienen en cuenta, en su formación profesional, en lo integral que deben ser sus decisiones, y finalmente en los intereses que tiene en su vida política.

\section{BIBLIOGRAFÍA}

Abello, C. (1998) El Derecho Laboral y La Constitución de 1991. Barranquilla. Editorial Mejoras Limitada. Primera parte.

Aristóteles. (s.f.), La Política. Libro VI.

Cassagne, J. (2009) El Principio de Legalidad y El Control Judicial de la Discrecionalidad Administrativa. Buenos Aires. Marcial Pons Argentina, S.A 1ra edición. 
Colombia. Congreso de la República. (1790). Ley 16 de 1790 Organización Vol. 6, No. 1 Diciembre de 2014 pp. 150 - 164 Judicial

Colombia. Colombia. Congreso de la República. (2000). Ley 599 de 2000.

Colombia. Consejo de Estado Colombiano 2, 26 de Marzo 2014. (0263-13).

Colombia. Asamblea Nacional Constituyente. (2011). Constitución Política Colombiana de 1991. Bogotá: Leyer.

Colombia. Corte Constitucional. (1995). Sentencia T-518. M.P. Vladimiro Naranjo Mesa.

Colombia. Corte Constitucional. (2002). Sentencia C-155. M.P. Clara Inés Vargas Hernández.

Colombia. Corte Constitucional. (2004). Sentencia T-056. M.P. Marco Monrroy Cabra.

Fernández, T. (2005). Del Arbitrio y de la Arbitrariedad Judicial. Madrid: lustel Portal de Derecho.

Fernández, T. (2008). De la Arbitrariedad de la Administración. 5a . Ed. Madrid: Aranzadi.

Gordillo, A. (2013). Tratado de Derecho Administrativo. Buenos Aires.

Henao, J. (2013). Panorama del Derecho Constitucional Colombiano. 4a . Ed. Bogotá: Temis. 
Kelsen, H. (1953). Traduc. M. Nilue. Teoría Pura del Derecho. Buenos Aires: Edición Francesa,

La Biblia. (s.f). El Éxodo.

Rodríguez, L. (2011). Derecho Administrativo General y colombiano. 17a. Ed. Bogotá: Temis.

Streck, L. (2013). Hermenéutica y Decisión Judicial. Bogotá: Grupo Editorial lbáñez.

Velásquez, F. (2010). Manual de Derecho Penal. 14a . Ed. Bogotá: Ediciones Jurídicas Andrés Morales.

Younes, D. (2014). Curso de Derecho Administrativo. 9ª Ed. Bogotá: Temis. 